I Universidade do Estado do Rio de Janeiro (Uerj),

Instituto de Estudos Sociais e Políticos (Iesp), Rio de Janeiro, RJ, Brasil

marianacavalcanti@iesp.uerj.br

\title{
QUANTO VALE UMA FAVELA ${ }^{1}$
}

\section{comentário Mariana Cavalcanti'}

Anthony Leeds

Uma regra geral de toda ciência para a observação de qualquer sistema: interferir com ele o menos possível e, na medida do possível, observá-lo como se não se estivesse presente e o sistema estivesse funcionando in natura com suas próprias regras. No momento em que o observador interage com, age sobre ou interfere nele, cria um novo sistema com novas regras que incluem o próprio observador como parte do sistema, com todos os seus pontos de vista, atualizados ou não, todos os seus preconceitos, etc. como regras também do sistema.

Por isso:

I) não se pode determinar como o sistema funciona, sem o observador;

2) não se pode determinar direções alternativas pelas quais o sistema pode evoluir como resultado de tipos variados de intervenção;

3) o observador exclui possibilidades de escolha, uma, algumas ou a maioria das quais podem ser mais desejáveis do ponto de vista de um certo valor em que se baseia uma política pública do que aquela escolha de fato adotada em uma intervenção ativa.

Portanto:

I) como cientista social, tenta-se evitar ou minimizar toda possível interação com o sistema;

2) intervenções de tipo programático devem ser estritamente evitadas durante o período de observação; 
3) a ideia de "ação-pesquisa" é uma contradição, em termos e metodológica;

4) deve ser evitada ao máximo a intervenção ideológica do pesquisador durante a observação e análise dos dados, isto é, o uso de ideias, conceitos, premissas e pressuposições com base em valores enviesados;

5) o observador, imperfeito como é, deve tentar controlar suas tendências de distorção e viés (bias) por meio de contínuos contrastes e comparações de casos tipologicamente semelhantes e diferentes - e derivar um modelo geral para todos os casos. Por exemplo:

A) comparar e contrastar outros países com o fenômeno favela (todos os assim chamados países subdesenvolvidos e capitalistas);

B) outros tipos de habitação popular ou proletária no mesmo lugar;

C) outros casos do fenômeno favela dentro do mesmo país;

D) o escopo mais amplo de pontos de vista relativos a qualquer categoria do fenômeno estudado.

Em geral, tentei observar todas essas regras e formular o modelo explicativo mais geral para o fenômeno favela. E evitei a tomada de decisões e de ações no que diz respeito a diretrizes de política pública sobre as favelas. Apresento a seguir uma série de proposições a respeito delas.

I) Frases como "o problema das favelas", "a favela como problema social" são enganosas e podem ser consideradas falsas por várias razões.

A) Sociedades podem ser vistas como sistemas; esses sistemas se encontram em vários estados e mostram "sintomas" característicos.

B) Favelas são "sintomas" de sistemas socioeconômicos em certos estados ou condições.

C) Como sintoma, as favelas representam uma gama de respostas de indivíduos e grupos inseridos no sistema socioeconômico como tentativas de resolver o que eles consideram problemas da melhor maneira possível.

D) Outras soluções, do ponto de vista habitacional, a esses problemas são as casas de cômodo, cabeças de porco, parques proletários, conjuntos, vilas proletárias, vilas operárias, casas de subúrbios etc.

E) Do ponto de vista habitacional, as favelas representam simplesmente uma entre um conjunto de escolhas, cada qual acompanhada - em circunstâncias atuais que tendem a persistir no longo prazo - de dificuldades características.

F) As causas genéricas condicionantes de todas as dificuldades em ter escolhas de habitações são salários reais baixos, representados por um salário mínimo que, frente aos custos de vida, é totalmente absurdo.

G) Essa condição de baixo salário aplica-se a todo o proletariado e a uma parte significativa das assim chamadas classes médias, as quais também se acham comprimidas no mercado habitacional e têm, como consequência, muitos de seus membros morando nas favelas. 
Em resumo, se se deseja falar em termos de "problema", não existe "o problema da favela"; existe, sim, um "problema" da mão de obra proletária e da classe média baixa em uma chamada economia subdesenvolvida.

II) Expressões como "favelado", usadas pelo povo em geral, e especialmente pelas elites, e mesmo por cientistas sociais, além do tom de desprezo que carregam, são categorias ideológicas e muito enganadoras, porque indicam um estado de ser e não uma condição mais ou menos temporária de vida, resultante de causas exteriores. Ou deve-se parar de usar o termo ou acrescentar termos como “cabeçado de porco", "conjuntado", "Jkado”, ou mesmo "apartamentado".

A) Quase todos os moradores de favela residiram em outros tipos habitacionais antes de ir para a favela: casas de família, casas particulares na rua, apartamentos, cabeças de porco etc.

B) Para muitos, a transferência para a favela é uma libertação, uma luta pela independência, significa encontrar um modo residencial apropriado - em suma, uma ampla melhoria, deliberadamente escolhida, em relação a condições habitacionais anteriores. Esses são aspectos de "quanto vale uma favela".

C) Moradores das favelas são íntima e totalmente integrados ao mercado de trabalho, ao comércio e à política da cidade. Todas as indicações mostram que eles, geralmente, são mais integrados em todos esses sentidos do que os "cabeçados de porco", os "conjuntados", os "Jkados". O mito ideológico do isolamento dos moradores de favela contido no termo "favelado", porém, conduz até os cientistas sociais a reiterar os mitos da falta de integração dos chamados "favelados"; a deixar de estudar aqueles outros tipos habitacionais para descobrir como suas populações são semelhantes ou diferentes em termos de ocupação, qualificação profissional, renda, atividade política, estabilidade familiar etc; e a perpetuar o mito da marginalidade do "favelado" como se esta fosse algo intrínseco a ele em vez de revelar a "marginalização" geral de quase todo o proletariado e de grande parte da classe média baixa pelas instituições da sociedade em seu contexto de subdesenvolvimento.

D) A transferência para a favela, para grande porcentagem dos moradores das favelas, permite a manutenção de uma integração bastante plena com a sociedade global ou até uma reintegração na sociedade, a partir de uma posição marginalizada, econômica ou socialmente, como quando se mora em uma casa de cômodos. Esse é outro aspecto de "quanto vale uma favela".

III) A gama inteira de escolhas habitacionais faz parte de uma gama maior de alternativas entre as quais se tem de escolher. Falando do proletariado e da classe média baixa (pelo menos):

A) eles têm de escolher, com recursos muito escassos, entre priorizar sua própria geração ou a geração futura, em criação; 
B) eles têm de decidir em quais esferas da vida alocar mais recursos: educação, habitação, investimentos, vestuário, alimentação etc., ou chegar a um equilíbrio entre elas;

C) eles têm de escolher entre estilos de vida que conferem prestígio e desprezo, tendo em vista as vantagens de um ou de outro;

D) eles têm de escolher entre diferentes motivos pessoais como a busca de poder ou influência, ou a procura de segurança pessoal ou familiar.

Em resumo, a escolha não é entre um tipo habitacional e outro, mas sim entre maneiras de viver a fim de alcançar determinadas metas.

IV) Na minha experiência, a maioria dos moradores de favela fez essa escolha habitacional por lhe permitir satisfazer ao máximo outros valores, como educação, saúde, ganhar dinheiro, liberdade pessoal, melhor moradia, estabilidade familiar etc. Esse é um terceiro aspecto de "quanto vale uma favela".

V) Do ponto de vista do funcionamento do sistema social, para as pessoas proletárias e da classe média baixa de baixa renda, a favela representa uma solução parcial para muitos problemas.

A) O sistema social inclui uma série de instituições que empobrecem o trabalhador:

I) o sistema salarial vigente;

2) o controle centralizado do governo sobre os sindicatos de trabalhadores, o qual reduz a capacidade de negociação em prol de interesses da classe;

3) a sociologia da saúde que mostra como estar doente reduz o poder de ganhar, o poder aquisitivo e aumenta os custos em proporção inversa à renda, percentualmente, para os pobres;

4) os abusos, vastamente espalhados, do sistema da carteira assinada;

5) os custos da educação, muitos dos quais são financiados pelas próprias pessoas, e que têm efeitos discriminadores, por exemplo, os gastos com livros e uniformes escolares. Além desses custos, a lei do primário completo também tem efeito discriminador;

6) a estrutura excludente do sistema escolar - vestibular e ginásio pagos eliminam cerca de $95 \%$ do proletariado e não muito menos da classe média baixa;

7) o sistema de aluguéis;

8) o sistema de pagamentos para casas próprias;

9) um sistema de impostos exigente e regressivo que aumenta percentualmente e de forma desigual os custos dos gêneros e bens de consumo para rendas grandes e pequenas.

Todas essas e outras instituições continuam a ser mantidas pelos sistemas formais e informais de poder da sociedade. 
B) $\mathrm{Na}$ contabilidade das rendas de famílias institucionalmente empobrecidas, a residência na favela representa uma poupança. Capitais familiares - nas favelas menos afetados por pagamentos de aluguéis, juros, impostos territoriais etc. - podem ser usados para outros fins:

I) educação própria ou dos filhos;

2) melhorar ou manter a saúde e aumentar o poder aquisitivo;

3) roupa;

4) comer melhor;

5) gozar melhor a vida;

6) poupanças visando a investimentos que levem a investimentos futuros, por exemplo, comprar geladeira;

7) investir para aumentar capital e ganhos, como em casas comerciais ou fábricas;

8) investir em terrenos ou casas para extrair renda ou mesmo para morar;

9) investir na própria casa para mais conforto ou a fim de depois vender ou trocar por uma melhor.

C) A flexibilidade da moradia da favela do ponto de visa da construção pode ser vista como sistema de segurança social operacional para a família estendida no contexto de mau funcionamento das instituições e do instituto de previdência e das rendas baixas.

Nenhum outro tipo de moradia pode ser adaptado ou é tão adaptável às necessidades cambiantes da família estendida ao longo do tempo, ao capital variável da família, e aos períodos de tranquilidade e crises.

D) As favelas consistem em uma solução desregulada para o problema do espaço urbano no contexto de zoneamento, habitação e planejamento inadequados. São áreas de crescimento urbano "natural" em que o crescimento urbano regulado e planejado não consegue acompanhar as necessidades no contexto de uma condição nacional de "subdesenvolvimento".

E) Morar em favelas é uma solução para uma situação de aluguéis inviável, dada a estrutura absurda de salários. A estrutura salarial é questão de diretriz de política pública nacional, somente limitadamente ligada ao nível de qualificação profissional da mão de obra em geral.

F) As favelas são muitas vezes uma solução para produtividade extra por parte dos moradores, porque tanto a casa quanto o terreno podem ser usados para produzir - note-se que a economia agrária especializada que se encontra em muitas favelas contribui para a poupança ou mesmo para as rendas domiciliares. Tal produção é quase impossível nos conjuntos, cabeças de porco, parques proletários etc. e constitui uma solução parcial diante dos altos preços dos gêneros.

G) As favelas consistem em uma solução para meios de transporte totalmente inadequados, cujos custos são altos relativamente aos salários. As favelas são 
uma solução em termos de tempo, dinheiro, saúde (evitando o cansaço), convivência familiar. Deve-se notar aqui o caminho de migração, dentro da área metropolitana, partindo de áreas de habitações empobrecidas reguladas, como casas de cômodo, em direção às favelas, aos subúrbios, ou de vilas, como a Vila Kennedy, de volta para as favelas ou outros tipos de moradia dentro da cidade. Todas essas soluções são aspectos de "quanto vale uma favela".

VI) Supondo que não haja restrições ao crescimento da favela, tais como proibições de construção impostas de fora (ou de dentro) da favela ou devidas à questão geológica, parece ocorrer uma progressão evolucionária normal. Para aquelas favelas mais adiantadas em sua evolução, podem-se fazer as seguintes proposições:

A) desenvolvem um mercado de trabalho interno bastante grande;

B) desenvolvem comércio e indústria apreciáveis;

C) mostram a crescente tendência de regular seus próprios sistemas de água, luz, esgoto, ruas e escadas;

D) apresentam possíveis freguesias para profissionais liberais, como médicos, dentistas, advogados, professores, alguns dos quais se tornam moradores da favela;

E) apresentam freguesias importantes para manipulação política, como eleitorados etc. que requerem, por exemplo, capitais em troca de votos;

F) a combinação de mercado de trabalho interno, comércio, indústria, arranjo físico, moradores profissionais, interesses políticos intensifica a entrada de capitais;

G) os capitais que entram se destinam em parte ao melhoramento das moradias e da infraestrutura da favela tanto quanto a outros investimentos.

Podemos dar o exemplo da favela mais desenvolvida: Jacarezinho.

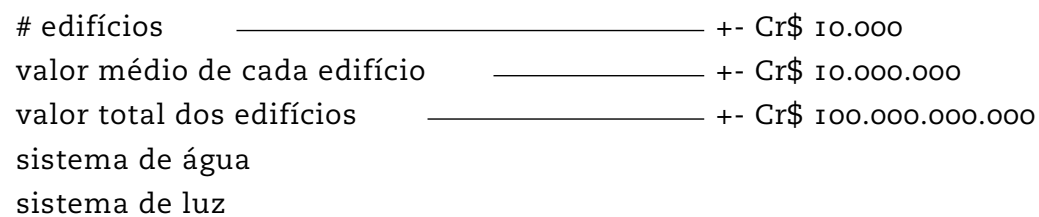

vias de acesso, escadas, ruas etc.

sistema de esgotos

US $\$ 30,000,000$

inventários e estoques

máquinas e implementos

carros e caminhões

total mínimo

60.000 .000

Com Jacarezinho pode-se apurar, numa escala menor, Barreira do Vasco, Parque União, Rocinha, Nova Brasília, Borel, Morro União, Parque de Alegria, e outras. Essas considerações constituem outro aspecto de "quanto vale uma favela". 
VII) Supondo a existência de restrições, o investimento nas favelas varia de acordo com a condição do mercado de trabalho circundante. Parece que um fator importantíssimo é a disponibilidade de empregos na indústria para trabalhadoras mulheres treinadas, como é o caso no Méier (tecelagem, barbantes, eletrônicos etc.) enquanto em Ramos esses tipos de emprego para mulheres são poucos, e o trabalho doméstico é muito mal pago. Na Gávea mulheres podem encontrar não só empregos que exigem treinamento, mas também o trabalho doméstico é relativamente bem pago e acessível no Leblon, na Gávea, em Ipanema e em Copacabana. Em consequência, ainda que com restrições, as favelas da Gávea são áreas de crescimento, investimentos e melhoramento relativamente bem desenvolvidas. Em regra, favelas pequenas com restrições relacionadas a um mercado de trabalho limitado são aglomerações de casebres e barracos deprimidas e subdesenvolvidas, em forte contraste com favelas como Parque União ou Jacarezinho, que têm edifícios de três e quatro andares de concreto armado, lajota e laje.

VIII) Supondo como base a existência de I80.000 edifícios - barracos e casas - nas favelas da Guanabara, com o valor médio em materiais de 4,000,000, incluindo luz e água dentro de casa, o valor total seria aproximadamente US\$240,000,000 sem contar os sistemas de iluminação pública, de esgotos e de água; as vias de acesso, escadas, e pavimentações; as lixeiras; nem os inventários, estoques, máquinas etc. O total global da construção e desses outros investimentos será, talvez, da ordem de US\$ 600,000,000 sem contar mão de obra, administração, custos de financiamento, planejamento etc. Tudo isso configura um aspecto de "quanto vale uma favela".

Em conclusão:

I) as favelas são respostas a um certo tipo de sistema social e econômico, bem difundido no mundo de hoje.

2) Em regra, as favelas são áreas urbanas de crescimento "natural".

3) Em geral, as favelas representam tentativas de soluções correlacionadas para um conjunto de problemas tal como definidos pelos integrantes da sociedade.

4) As favelas mostram êxitos irregulares na solução desses problemas, porque, de fato, não são reconhecidas por autoridades nem regularizadas, são extralegais, espontâneas e não planejadas. Algumas favelas são fracassos desastrosos e desesperados, condição determinada por causas externas à favela.

5) Em geral, as favelas resolveram os problemas definidos de maneiras melhores do que outras tentativas, uma vez que são mais adaptadas tanto às reais condições socioeconômicas externas como às reais estruturas e necessidades internas dos domicílios e suas extensões familiares.

6) As favelas continuarão a crescer enquanto persistirem as formas características da economia nacional e suas manifestações em aluguéis locais e salários. 


\section{COMENTÁRIO}

\section{"QUANTO VALE UMA FAVELA": ECONOMIA, TRABALHO E A CIDADE NA VIDA COTIDIANA}

Conferência proferida há 50 anos no Museu de Arte Moderna do Rio, "Quanto vale uma favela" é, no original, mais um resumo analítico de ideias que Leeds vinha desenvolvendo em seu trabalho de campo nas favelas cariocas do que propriamente um ensaio ou texto acadêmico. Manuscritos nos típicos legal pads norte-americanos em que Leeds fazia a maior parte de suas notas de pesquisa e de campo - como lembrou seu "filhote ligeiramente rebelde", Luiz Antonio Machado da Silva, em apresentação à última edição de A sociologia do Brasil urbano (Leeds \& Leeds, 20I5) - os I 3 "papeizinhos amarelos" contêm rasuras, rabiscos, e denunciam ao menos uma troca de caneta, além de incluir em suas margens anotações a lápis e contas aparentemente não relacionadas ao texto.

A apresentação está escrita em inglês, mas o modo como desenvolve o argumento é entremeado por expressões e palavras em português. Alguns desses termos poderiam ser facilmente traduzidos para o inglês - "comer melhor", "geladeira", "poupança", "uniformes escolares", "freguesia" - e seu uso em português parece marcá-los como categorias nativas, condensando sentidos e ideiaschave do mundo que descrevem. As frases compostas em português e inglês evidenciam a intimidade de Leeds não só com a vida cotidiana das favelas, resultado de extenso trabalho de campo, mas também uma familiaridade com um português mais técnico ou acadêmico que lhe parece expressar melhor certas condições conjunturais do que sua língua nativa: "in the contabilidade of famílias institucionalmente empobrecidas the favela residence represents a poupança", "the vastamente espalhados abusos do sistema de carteira assinada" e ainda "poupança or incomes".

Uma das expressões recorrentes em português é justamente "quanto vale uma favela" - que, curiosamente, não encabeça o documento original, sem título. Isso pode indicar que o texto tenha sido uma demanda externa, uma espécie de encomenda dos organizadores do evento ou do jornalista Paulo Alberto, que, segundo Rachel Viana (20I4: I4I), publicou partes da conferência em sua coluna no jornal Última Hora em 22 e 23 de agosto de i 968 , ou seja, dias após a conferência. De todo modo, a recorrência da expressão entre aspas e em português, entremeando proposições mais gerais sobre as favelas cariocas, é digna de nota.

Sabemos, por conta da pesquisa de Rachel Viana (2014) sobre a atuação de Leeds no Brasil, que ele passara grande parte de I 968 envolvido em uma pesquisa a ser desenvolvida pelo Centro Nacional de Pesquisas Habitacionais (Cenpha) em conjunto com o Instituto de Ambiente Urbano da Universidade de Columbia, em que atuaria como consultor. Intitulada "Formação de capital para a habitação", incluía extenso survey sobre economia domiciliar. Ao que tudo indica, a pesquisa não foi desenvolvida nem na escala, nem nos locais inicialmente planejados. Entretanto, a julgar por "Quanto vale uma favela" e outros 
documentos em que Leeds elabora o tema dos investimentos em infraestrutura das favelas, evidencia-se que a questão dos capitais das e nas favelas já vinha sendo objeto de coleta de dados em pesquisas anteriores. Assim, a quantificação aqui presente depende também da compreensão dos aspectos qualitativos do cotidiano das favelas.

Apesar do cuidado com a esquematização por meio da qual Leeds desdobra seus argumentos sobre "quanto vale uma favela", os diferentes aspectos que pontua como dimensões de valor da favela não coincidem exatamente com suas proposições sobre as favelas em geral. As proposições se desdobram em outra chave: a descrição de um sistema capitalista e subdesenvolvido a partir de sua ponta. Sobre o sistema societário em si e as particularidades do desenvolvimento urbano em contexto subdesenvolvidos, o texto apresenta ideias já familiares ao leitor de A sociologia do Brasil urbano. A questão de "quanto vale uma favela", apesar de não ser inédita na obra de Leeds, por sua vez, parece particularmente fértil para um leitor de hoje, tanto por lançar luz sobre o presente etnográfico de seu trabalho de campo nos anos ig6o quanto pelo potencial de iluminar questões que marcariam debates mantidos nos estudos urbanos, incluídas pesquisas bem recentes, nas cidades do dito "sul global", também feitas a partir da análise de práticas cotidianas em que, entre a economia, o trabalho e a produção da cidade, se encontram imbricadas.

Neste breve comentário, portanto, dedico-me justamente a elaborar o modo como Leeds constrói um modelo sistêmico e multiescalar a partir da observação e análise da vida cotidiana. No intuito de chegar a um modelo analítico que descreva o desenvolvimento das favelas ao longo do tempo, ele se vale de descrições etnográficas da vida cotidiana que, uma vez sintetizadas, possibilitam a descrição do circuito de investimentos ou de acumulação de capital, na forma da infraestrutura na favela. Ao fazê-lo, põe em relevo os pequenos investimentos e estratégias da economia cotidiana que tornam legível o modo como a favela e a cidade se coproduzem - há mais de 50 anos.

\section{SEIS DIMENSÕES DO VALOR DAS FAVELAS}

Uma dimensão inicial do valor das favelas é relacional e implica assumir o ponto de vista de um proletário, levando em consideração trajetórias possíveis e contingenciais. As duas primeiras proposições gerais acerca das favelas desmontam o que Leeds identifica como uma construção ideológica da questão que opera por meio da reificação do espaço da favela e essencialização da categoria do favelado. As favelas não são um problema em si, e sim sintoma do estágio de desenvolvimento de um sistema societário que é econômico, nacional e desigual porque subdesenvolvido. A questão das favelas não é urbanística, mas expressão e consequência da estrutura do mercado de trabalho: "exis te, sim, um problema da mão de obra proletária e de classe média baixa numa economia 'subdesenvolvida' assim chamada". 
Leeds afirma que a falácia ideológica afeta também a leitura de alguns cientistas sociais que, ao identificar no favelado o sujeito da marginalidade, reduzem uma questão de classe a um determinismo ecológico e confundem uma suposta essência com uma condição mais ou menos temporária. Equivalentes estruturais da favela são as casas de cômodos, os cortiços ou os conjuntos habitacionais. Cada uma dessas tipologias habitacionais constitui, para Leeds, um modo de vida que é muitas vezes deliberadamente escolhido - determinado por certas escolhas que fazem sentido dentro das trajetórias habitacionais dos trabalhadores. Uma segunda dimensão do valor das favelas é, portanto, comparativa: reside na maior integração "com o mercado de trabalho da cidade, com o comércio, a política da cidade" que esses espaços proporcionam a seus moradores, quando comparadas aos cortiços, conjuntos habitacionais ou casas de cômodos.

Esses diferentes modos de vida são respostas possíveis a uma situação comum de baixos salários e altos aluguéis em um contexto institucional formal e informal que impõe escolhas e sacrifícios, realizados por sujeitos situados, dotados de trajetórias particulares e respondendo a urgências cotidianas: “a escolha não é entre um tipo habitacional e outro mas sim entre uma maneira de viver e uma outra maneira de viver para alcançar umas metas determinadas". Eis então a terceira dimensão de "quanto vale uma favela": o modo de vida possibilitado pela favela é orientado para o futuro, constitui um tipo específico de acumulação ou de investimento. Assim, escreve Leeds, viver na favela significa privilegiar certos valores, em detrimento de outros: a educação própria ou dos filhos, saúde, vestuário, comida, lazer, investimentos em bens permanentes como geladeiras, em pequenos estabelecimentos comerciais e na própria casa.

Todos esses "valores" apontados por Leeds são orientados para melhorias individuais ou familiares, a atingir no futuro. A singularidade da favela como forma urbana reside no fato de constituírem o que chama de "áreas de crescimento natural", isto é, de se desenvolverem sem as restrições da regulação institucional da cidade dita formal. A favela oferece uma solução habitacional dentro de um quadro de escassez e urgência, mas não ausência de agência ou de futuro: "a residência na favela representa uma poupança", isto é, libera parte da renda que seria gasta em aluguéis, impostos e transporte para investimentos futuros; é uma forma de acumulação. Garante ao mesmo tempo permanência e condições de adaptabilidade a uma conjuntura marcada pela instabilidade.

O quarto aspecto de "quanto vale uma favela" deriva da espacialidade própria da favela, do fato de elas constituírem as ditas áreas de crescimento urbano natural. Trata-se de um argumento que desnaturaliza a materialidade da favela. Se na narrativa ideológica e hegemônica a espacialidade da favela é identificada com marginalidade, sem mediações ou problematizações, no modelo de Leeds ela é reconstruída como lugar de investimentos materiais e sub- 
jetivos. ${ }^{2}$ Essa característica permite pensá-la como um espaço não apenas de reprodução social, mas que também admite ou possibilita diversos tipos de produção.

Isso é evidenciado na síntese etnográfica que fundamenta sua análise da casa na favela. A casa na favela abre possibilidades interpretativas do entrecruzamento de grandes processos econômicos, de atividades produtivas, e de construção de futuro e sentido para e na vida cotidiana. Constitui "poupança" (palavra sistematicamente mantida no original em português ao longo do texto, vale assinalar), ao suprimir os custos de aluguel e de transporte embutidos em outras alternativas residenciais acessíveis ao proletariado e às classes médias baixas. Oferece às famílias um "sistema de segurança social em funcionamento", por sua plasticidade e adaptabilidade física que permitem a transformação do espaço da casa de acordo com chegadas de novos membros da família e adaptações a diferentes fases dos ciclos de vida das famílias; permite ainda o compartilhamento do cuidado dos filhos e a colaboração no preparo das refeições e pequenos reparos ou obras domésticas. Essa plasticidade também permite o desenvolvimento do que os urbanistas da cidade dita formal gostam de elogiar como "uso misto": as construções podem e devem abrigar espaços de moradia, comércio e de produção. Pequenos estabelecimentos comerciais, ateliês, bares, e salões de beleza se acoplam aos espaços domésticos, ou deles são "puxados", possibilitando a geração de novos capitais que serão reinvestidos em infraestrutura ou usufruídos como melhoria de vida. Pequenas criações de animais, de legumes e verduras também contribuem para a alimentação das famílias. Por tudo isso - pelos investimentos materiais nela contidos - a casa na favela também constitui uma mercadoria, real ou potencial, ou fonte de valor, por meio de aluguéis de quartos ou cômodos.

Já a quinta dimensão de "quanto vale uma favela" amplia a escala de análise da materialidade de cada casa ou edifício para considerar também a infraestrutura da favela - que incluiria, para Leeds, o valor total dos edifícios, dos sistemas de água, de luz, vias de acesso, escadas, ruas, sistema de esgotos, inventários e estoques, máquinas e implementos, carros e caminhões... em suma, leva em conta tanto o acúmulo de investimentos quanto o trabalho cotidiano envolvido na manutenção das materialidades das favelas ao incluir, na sequência desse inventário que elenca todo um patrimônio das favelas, mão de obra e administração.

A premissa de que as favelas constituem áreas de crescimento urbano natural implica a concatenação de uma escala evolutiva, em que o Jacarezinho figura, no final dos anos I960, como a favela "mais desenvolvida" da Guanabara. Leeds conhecia profundamente a vida cotidiana e a estrutura social do Jacarezinho, tendo lá morado por longos períodos de tempo, e contribuído financeiramente para uma Associação de Moradores administrada por seu assistente e interlocutor-chave Flavio Romano (no arquivo abrigado na COC há extensa corres- 
pondência entre os dois). É dessa experiência, em grande medida, que vem a defesa da favela como solução para os dilemas da integração dos proletários.

Desde o Jacarezinho, Leeds sugere que favelas "mais adiantadas em sua evolução" desenvolvem mercado de trabalho interno, bem como comércio e indústria; desenvolvem mecanismos de produção e manutenção de infraestrutura, como sistemas de água, luz, esgotos e escadas; constituem "freguesias" de profissionais liberais e também em termos de trocas políticas. A combinação desses elementos, segundo Leeds, intensifica a entrada de capitais, na forma de novos investimentos nas moradias e nas atividades produtivas. Favelas mais "evoluídas", em que se encontram "edifícios de 3 e 4 andares de concreto armado, lajota e laje" são, portanto, aquelas em que os diferentes mercados - de trabalho, imobiliário, de serviços e político - se encontram mais consolidados, como no Jacarezinho. Vale notar que a maior parte das favelas que ele nomeia como "evoluídas" era localizada na Zona Norte, no entorno de regiões industriais da cidade.

Leeds calcula o valor de então da favela do Jacarezinho em 60 milhões de dólares. Na conversão trivial de um aplicativo de deflação, ${ }^{3}$ esse montante seria hoje estimado em US\$ 43I,975,862.07, ou seja, um pouco menos de 432 milhões de dólares, numa taxa de inflação acumulada de $620 \%$.

Finalmente, no sexto aspecto explicitamente enumerado de "quanto vale uma favela", Leeds extrapola o cálculo do Jacarezinho ou outras favelas consolidadas para o estado da Guanabara, estimando o valor global de I 80.000 edifícios em cerca de 240 milhões de dólares. Se incluídos os investimentos em infraestrutura, Leeds aventa a possibilidade de investimentos da ordem de 600 milhões de dólares para as favelas da Guanabara. Isso "sem contar mão de obra, administração, os custos de financiamento, planejamento, etc.”. Rachel Viana chama a atenção para pelo menos outra ocasião em que Leeds realiza esse cálculo, em carta para Chester Rapkin, na qual estima que o "montante de capital envolvido somente em construções, inventários, máquinas, sistemas de água e luz girariam em torno de US\$600.000.000 a US\$ I.500.000.000, em uma conjuntura em que o orçamento do estado da Guanabara seria em torno de $\$$ 400.000.000" (Viana, 2014: I30-I3I).

\section{TRABALHO, INFRAESTRUTURA E COTIDIANO: AGENDAS CINQUENTENÁRIAS DE PESOUISA}

Concluo este breve comentário sobre a dimensão do valor nas favelas para Leeds reconstituindo os percursos de seu argumento, e apontando para debates contemporâneos que suas ideias antecipam ou poderiam iluminar.

Leeds começa desmontando a reificação das favelas como espaços de pobreza extrema habitados por seres essencial e estaticamente marginalizados. Sua etnografia da favela como "ponta" de um sistema societário nacional e subdesenvolvido substitui a opacidade da ideia de marginalidade pela complexidade da descrição de seus aspectos produtivos. Adotando o ponto de vista 
dos atores sociais, constrói uma perspectiva relacional e comparativa com as possibilidades de solucionar a secular questão da moradia das classes trabalhadoras nas cidades capitalistas, em que a favela figura como espaço vantajoso - seja pelo acesso facilitado aos serviços e mercados urbanos, seja pelas possibilidades adicionais de geração de renda por meio de investimentos nas moradias, negócios e produção agrícola em pequena escala. Esses investimentos geram melhorias materiais, das casas mas também da infraestrutura da favela. Quanto mais "desenvolvida” uma favela, mais capitais, oportunidades de negócios e serviços ela atrairá.

Os cálculos que acabam por extrapolar um suposto orçamento do estado da Guanabara constituem engenhosa quantificação de processos observados no cotidiano de residências, estabelecimentos comerciais, espaços de lazer e sociabilidade das favelas ao longo do tempo. Mais do que pelo cálculo preciso, o raciocínio de Leeds impressiona por sua plausibilidade e verossimilhança. A quantificação torna visíveis, legíveis e palpáveis os circuitos de acumulação e os mercados de trabalho e de moradia formados pelas e nas favelas. Esse movimento analítico antecipa pelo menos três debates que serão centrais para a compreensão da vida nas cidades ao longo das décadas seguintes.

Em primeiro lugar, o modelo de Leeds antecipa os debates em torno do setor informal da economia, que ganhariam força nos anos I970 e seriam renovados com os efeitos substantivos das reestruturações produtivas dos anos I980 e I990. O argumento de Leeds aqui apresentado se endereça à mesma conjuntura de textos clássicos e fundamentais para os debates acerca da informalidade no trabalho, como Mercados metropolitanos de trabalho manual e marginalidade, dissertação de mestrado de Luiz Antonio Machado da Silva concluída em I97I, ou as primeiras elaborações do antropólogo Keith Hart (I973) acerca do setor informal da economia a partir de seus estudos sobre oportunidades formais e informais de emprego e renda em Gana. Machado e Hart, cada um a seu modo e dentro de interlocuções específicas, tinham a preocupação de descrever o não contabilizado oficialmente, as atividades econômicas e construtivas que constituíam o cotidiano de grande parte dos trabalhadores de cidades ditas subdesenvolvidas.

Uma das condições de possibilidade do argumento de Leeds é sua completa desconsideração analítica de uma possível distinção entre mercados - de trabalho, de moradia, ou de serviços - formais e informais. Em suas conclusões ele argumenta que o crescimento natural das favelas nada tem a ver com a informalidade, e sim com seu entorno: quanto mais próspero o entorno, maior é a chance de desenvolvimento ou evolução da favela. ${ }^{4}$ A extralegalidade é constitutiva da forma favela, e não fator que determine seu sucesso ou fracasso, ou evolução. Nesse sentido, esses três trabalhos (e muitos outros da época) constroem um sentido para a informalidade que é diametralmente oposto à caracterização da questão por Hernando de Soto (2000), que ganharia força nos 
anos 2000, engendrando toda uma geração de políticas públicas de formalização da informalidade defendidas pelas agências multilaterais no contexto do neoliberalismo consolidado nos anos I990.

Em segundo lugar, Leeds desenvolve a estratégica analítica de "seguir" os capitais investidos nas favelas, para descrever o que considera sua lógica própria de acumulação e desenvolvimento urbano. Ao fazê-lo, empreende uma espécie de etnografia multissituada bem antes de o termo se popularizar, nos anos I 990 (ver Marcus, I995).

Além da complexidade notável do modelo de Leeds para a compreensão da realidade que constituía seu presente etnográfico, vale assinalar que as grandes transformações pelas quais as favelas passariam a partir dos anos I980 seriam a ele facilmente incorporáveis.

Uma agenda de pesquisas centrada nos investimentos em infraestrutura nas favelas cariocas hoje implica também perceber a centralidade das políticas públicas de urbanização e suas imbricações políticas com políticas de segurança pública. Seria particularmente interessante pensar a incorporação de outro circuito de acumulação e de capitais, representado pelo tráfico de drogas, que conectaria as favelas a outras localidades e escalas de ação, poder e conflito, historicamente produtoras de novas formas de mercadorias políticas (Misse, 2002) e novos padrões de sociabilidade (Silva, 2004). A materialidade e centralidade dos circuitos das drogas, armas, motos e outros objetos do "mundo do crime", tão bem analisados por Carolina Grillo (2013) em sua tese, acrescentariam camadas de complexidade e historicidade em uma possível contabilidade do valor das favelas nos moldes de Leeds nos dias de hoje. A contabilidade dos capitais na favela também permitiria a incorporação dos novos circuitos de investimento em infraestrutura nas favelas cariocas, representados pelos programas de urbanização de favelas, desenvolvidos em escalas cada vez mais amplas dos anos $1980 \mathrm{em}$ diante - Mutirão, Mutirão remunerado, Favela Bairro, PAC, Morar Carioca.

Finalmente, a estratégia de calcular os investimentos em infraestrutura, em termos de capital, das dimensões cotidianas das estratégias de vida e produção de futuros também antecipa pesquisas bastante recentes em torno das disputas a respeito da infraestrutura urbana nas cidades do dito sul global (Larkin, 20I3; Graham \& McFarlane, 20I5). Como Arjun Appadurai (20I5) notou em texto recente, a etnografia permite desnaturalizar a provisão de infraestrutura urbana para reconstituí-la como dimensão cotidiana da vida nas cidades. Cinquenta anos depois da conferência de Leeds no MAM, "quanto vale uma favela" é uma pergunta ainda capaz de sustentar uma robusta agenda de pesquisas etnográficas e multiescalares, particularmente no Rio de Janeiro em que os tiroteios e conflitos recrudescem em tempos de crise, em alguns lugares agora sob a sombra dos teleféricos desativados. 


\section{NOTAS}

I Conferência inédita proferida por Anthony Leeds no Museu de Arte Moderna (MAM), no Rio de Janeiro, em 20 de agosto de 1968. A edição realizada por Sociologia \& Antropologia leva em conta as versões em português e inglês dos manuscritos depositados no arquivo Leeds, custodiado na Casa de Oswaldo Cruz/Fiocruz.

2 Sobre esse aspecto da construção cotidiana do valor das e nas favelas, ver também Cavalcanti, 2009.

3 Disponível em <http://www.usinflationcalculator.com/>. Acesso em 29 maio 2018.

4 Essa intuição seria confirmada dez anos mais tarde, com a publicação de Passa-se uma casa, de Licia Valladares (1978), que também foi uma interlocutora fundamental de Leeds. Em sua análise do programa de remoções de favelas, Valladares desvenda as razões pelas quais moradores removidos para conjuntos habitacionais acabavam por "passar" suas casas nos conjuntos e retornar a favelas da Zona Sul do Rio de Janeiro.

Mariana Cavalcanti é doutora em antropologia pela Universidade de Chicago e professora do Departamento de Estudos Sociais do Iesp/Uerj. É bolsista de produtividade do CNPq (nível 2), Jovem Cientista do Nosso Estado (Faperj) e Procientista (Uerj). 


\section{REFERÊNCIAS BIBLIOGRÁFICAS}

Appadurai, Arjun. (2015). Foreword. In: Graham, Stephen \& McFarlane, Colin (eds). Infrastructural lifes: urban infrastructure in context. Oxon/New York: Routledge.

Cavalcanti, Mariana. (2009). Do barraco à casa: tempo, espaço e valor(es) em uma favela consolidada. Revista Brasileira de Ciências Sociais, 24/69, p. 69-80.

De Soto, Hernando. (2000). The mystery of capital: why capitalism triumphs in the West and fails everywhere else. New York: Basic Civitas Books.

Graham, Stephen \& McFarlane, Colin. (20I5). Infrastructural lifes: urban infrastructure in context. Oxon/New York: Routledge.

Grillo, Carolina. (2013). Coisas da vida no crime: tráfico e roubo em favelas cariocas. Tese de doutorado. PPGSA/Universidade Federal do Rio de Janeiro.

Hart, Keith. (1973). Informal income opportunities and urban employment in Ghana. The Journal of Modern African Studies, II/I, p. 6I-89.

Larkin, Brian. (2013). The politics and poetics of infrastructure. Annual Review of Anthropology, 42, p. 327-343.

Leeds, Anthony \& Leeds, Elizabeth. (2015). A sociologia do Brasil urbano. 2 ed. Rio de Janeiro: Editora Fiocruz/Faperj.

Marcus, George E. (I995). Ethnography in/of the world system: the emergence of multi-sited ethnography. Annual Review of Anthropology, 24/I, p. 95-II7.

Misse, Michel. (2002). Rio como bazar: a conversão da ilegalidade em mercadoria política. Insight Inteligência, 3/5, p. I2-I6.

Silva, Luiz Antonio Machado da. (2004). Sociabilidade violenta: por uma interpretação da criminalidade contemporânea no Brasil urbano. Sociedade e Estado, I9/I, p. 53-84. Silva, Luiz Antonio Machado da. (I97I) Mercados metropolitanos de trabalho manual e marginalidade. Dissertação de Mestrado. PPGAS/Museu Nacional/Universidade Federal do Rio de Janeiro. 
Valladares, Licia do Prado. (1978). Passa-se uma casa: análise do programa de remoções de favelas do Rio de Janeiro. Rio de Janeiro: Zahar.

Viana, Rachel de Almeida. (2014). Antropologia, desenvolvimento e favelas: a atuação de Anthony Leeds na década de I960. Dissertação de Mestrado. PPGHCS/Casa de Oswaldo Cruz/ Fiocruz. 


\section{QUANTO VALE UMA FAVELA}

Resumo

O artigo reúne e divulga pela pela primeira o texto da conferência inédita proferida em I 968 por Anthony Leeds no Museu de Arte Moderna do Rio de Janeiro, acompanhado de comentário de Mariana Cavalcanti. Nela, Leeds aborda de modo inovador o tema dos investimentos em infraestrutura e dos capitais que circulavam nas favelas cariocas ao criticar a visão então hegemônica da favela como um problema, discutindo essa alternativa de localidade de moradia a partir da agência dos trabalhadores urbanos e como um projeto de vida nas cidades diante de uma situação de profunda desigualdade. A vida cotidiana constitui o ponto de partida para Leeds construir um modelo de análise que dê conta dos processos pelos quais favela e cidade se coproduzem. O texto prefigura ainda debates posteriores do autor sobre o uso da etnografia multissituada e a desmistificação da teoria da marginalidade e da cultura da pobreza.

\section{HOW MUCH IS A FAVELA WORTH}

Abstract

The article publishes for the first time the lecture given in I 968 by Anthony Leeds at the Rio de Janeiro Museum of Modern Art, accompanied by comments from Mariana Cavalcanti. In this talk, Leeds takes an innovative approach to the theme of the infrastructural investments and capital circulating in Rio's favelas by criticizing the view prevalent at the time of the favela as a problem. Instead he discusses this alternative residential location through the agency of urban workers, as an urban life project that responds to a situation of deep inequality. Everyday life comprises the starting point for Leeds to build an analytic model capable of accounting for the processes through which favela and city are coproduced. The text also prefigures the author's later debates on the use of multisite ethnography and the demystification of the theory of marginality and the culture of poverty.
Palavras-chave

Anthony Leeds;

favelas;

trabalhadores urbanos; cultura da pobreza; antropologia urbana.

\section{Keywords}

Anthony Leeds;

favelas; urban workers; culture of poverty; urban Anthropology. 